\title{
HLA-DQ Gene Complementation and Other Histocompatibility Relationships in Man with the Anti-Ro/SSA Autoantibody Response of Systemic Lupus Erythematosus
}

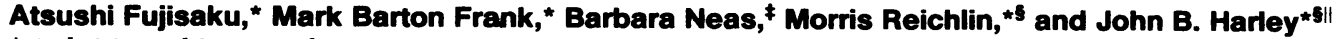 \\ ${ }^{*}$ Arthritis and Immunology Program, Oklahoma Medical Research Foundation, ${ }^{\ddagger}$ Department of Biostatistics \\ and Epidemiology, and ${ }^{\S}$ Department of Medicine, University of Oklahoma Health Sciences Center, \\ "Veterans Administration Medical Center, Oklahoma City, Oklahoma 73104
}

\begin{abstract}
A strong gene interaction between HLA-DQ1 and DQ2 alleles has been associated with anti-Ro/SSA autoantibodies (Harley, J. B., M. Reichlin, F. C. Arnett, E. L. Alexander, W. B. Bias, and T. T. Provost. 1986. Science [Wash. DC]. 232:1145-1147; Harley, J. B., A. S. Sestak, L. G. Willis, S. M. Fu, J. A. Hansen, and M. Reichlin. 1989. Arthritis Rheum. 32:826-836; Hamilton, R. G., J. B. Harley, W. B. Bias, M. Roebber, M. Reichlin, M. C. Hochberg, and F. C. Arnett. 1988. Arthritis Rheum. 31:496-505). To test a gene complementation mechanism for these results, restriction fragment length polymorphisms (RFLP) of the DQ $\alpha$ and $D Q \beta$ genes have been related to Ro/SSA precipitins in patients with systemic lupus erythematosus. In this study Ro/SSA precipitins are related to the simultaneous presence of a particular pair of RFLPs. A DQ $\alpha$ RFLP associated with HLA-DQ1 and a DQ $\beta$ RFLP associated with HLA-DQ2 predict that the $\alpha \beta$ heterodimer in HLA-DQ1/DQ2 heterozygotes is most closely related to antiRo/SSA autoantibodies, thereby supporting a gene complementation mechanism. Beyond this effect, an RFLP associated with HLA-DQ2 and/or DR7 is also related to Ro/SSA precipitins. Multiple molecular histocompatibility mechanisms are implicated, therefore, in the production of anti-Ro/SSA autoantibodies in autoimmune disease. For anti-Ro/SSA autoantibodies in SLE, and perhaps more generally, these data show that the histocompatibility antigens are among the elements that confer autoimmune response specificity and restrict the production of particular autoantibodies among patients with systemic lupus erythematosus. (J. Clin. Invest. 1990. 86:606611.) Key words: autoimmunity $\bullet$ HLA-DQ $\cdot$ gene complementation • SLE • immune response genes
\end{abstract}

\section{Introduction}

For many immunogens the immune responsiveness found in F1 mice but in neither parental inbred mouse strain is the consequence of gene complementation of the class II histocompatibility molecules $(1,2)$. Though abundant evidence exists that analogous dimeric $\alpha \beta$ molecules are present in man (3-5), examples of gene complementation demonstrating an in vivo human immune response are lacking. High titers of anti-

Address reprint requests to Dr. Harley, Oklahoma Medical Research Foundation, 825 N. E. Thirteenth Street, Oklahoma City, OK 73104. 1990.

Received for publication 22 May 1989 and in revised form 24 April

The Journal of Clinical Investigation, Inc.

Volume 86, August 1990, 606-611
Ro/SSA autoantibody predominate in HLA-DQ1/DQ2 heterozygous patients with primary Sjögren's syndrome (6) and systemic lupus erythematosus (SLE) $(7,8)$. This gene interaction effect may also be an instance of possible gene complementation of the immune response genes which is examined at the gene level in this study.

Ro/SSA is an RNA-protein complex of unknown cellular function composed of a peptide complexed with one of four small uridine-rich RNAs which are transcribed by RNA polymerase III (9). In addition to the well known $60-\mathrm{kD}$ Ro/SSA peptide (10-12), 52- and 54-kD peptides have been recently defined $(13,14)$. Available data also support binding of the 52 kD Ro/SSA peptide to the hY RNAs (13). Present evidence supports anti-Ro/SSA having an immunopathogenic role in congenital complete heart block as well as in some of the SLE and Sjögren's syndrome patients who have nephritis, sialadenitis, photosensitive dermatitis, or vasculitis (15-22).

To better understand the gene interaction at HLA-DQ associated with anti-Ro/SSA antibodies, we have analyzed the relationship between restriction fragment length polymorphisms (RFLP) ${ }^{1}$ of the DQ $\alpha$ and $\mathrm{DQ} \beta$ genes to HLA antigens and anti-Ro/SSA autoantibodies in SLE patients. Ro/SSA precipitins were found in nearly all SLE patients who had a particular pair of RFLPs. One is detected by a DQ $\alpha$ probe and associated with HLA-DQ1 positive SLE patients and the other RFLP is detected by a DQ $\beta$ probe in HLA-DQ2-positive patients. Moreover, this effect was stronger than any single allele whether defined by HLA serology or by RFLP analysis at HLA-DQ. Beyond this effect, however, a single RFLP was found to also be associated with Ro/SSA precipitins. These data not only show that gene complementation of HLA may be important in human immune responses, but also suggest that multiple molecular components of the normal immune apparatus determine the specificity of autoimmune responses.

\section{Methods}

Patients and anti-Ro/SSA antibody. Informed consent and peripheral blood was obtained from 76 patients who satisfied the 1982 revised American Rheumatism Association classification criteria for systemic lupus erythematosus (SLE) (23). Precipitating autoantibodies to Ro/ SSA were detected by Ouchterlony immunodiffusion against bovine spleen extract (24) and by counterimmunoelectrophoresis against human tissue extract (25). In this study, all sera gave the same results in these two tests when examined for precipitating anti-Ro/SSA autoantibodies.

HLA typing. Lymphocytes were prepared from heparinized peripheral blood by Ficoll separation and the fraction enriched for B lym-

1. Abbreviations used in this paper: RFLP, restriction fragment length polymorphism. 
phocytes was obtained with a nylon wool column. HLA-DQ and HLA-DR typing was performed with a complement-dependent microcytotoxic technique (26) using Terasaki HLA typing trays (One Lamda Inc., Los Angeles, CA).

Southern transfer. Genomic DNA was extracted from patient peripheral leukocytes with proteinase $\mathrm{K}$ digestion and phenol extraction, and digested completely with Bam HI, Eco RI, Eco RV, Hind III, Pst I, Pvu II or Taq I under conditions recommended by the restriction enzyme manufacturers. RFLPs at DQ were detected by Southern blotting of restriction enzyme digested DNA followed by hybridization to ${ }^{32} \mathrm{P}$ radiolabeled (27-29) DQ $\alpha$ or $\mathrm{DQ} \beta$ gene probes $(30,31)$ on nylon membranes (Biotrace RT; Gelman Scientific, Inc., Ann Arbor, MI).

Data analysis. Comparison of categorical variables has been evaluated using the two-tailed Fisher's exact test unless otherwise indicated. The F statistic is presented to appraise the relation between anti-Ro/ SSA and serologic or RFLP alleles and is taken from the analysis preliminary to the logistic regression procedure. Step-wise logistic regression analysis has been applied using the BMDP-LR program (32) with the presence of Ro/SSA precipitins as the dependent variable and selected RFLPs or serologic HLA-typing results as independent variables where step selections have been based upon the approximate asymptomatic covariance estimate. Briefly, the independent variable with the highest $F$ (if $F$ has $P<0.15$ ) enters the model first. After recalculating the model, the effects of all independent variables are reassessed. Independent variables are entered if the $F$ to enter has $P$ $<0.15$ or removed if the $F$ to remove has $P<0.10$ until none of the remaining independent variables pass the remove or enter limits.

Relevant serologic data were complete in 62 subjects and complete RFLP data were available from 67 subjects of the 76 SLE patients enrolled. 55 had both complete serologic and RFLP data. Each analysis was performed upon one of these overlapping cohorts.

\section{Results and Discussion}

Of the 62 patients with serologic HLA-typing of DQ1 and DQ2 alleles 15 of the 18 HLA-DQ1/DQ2 heterozygotes have a Ro/SSA precipitating antibody $(P=0.005$ compared to 21 of the remaining 44 patients by two-tailed Fisher's exact test) consistent with previous reports in Sjögren's syndrome and SLE patients $(6,8)$. For the entire SLE cohort, no HLA antigen allele nor genotype at HLA-DR or HLA-DQ is as powerfully associated with anti-Ro/SSA as is the HLA-DQ1/DQ2 heterozygous state.

70 RFLPs were identified in this population of SLE patients with seven restriction endonucleases (Bam HI, Eco RI, Eco RV, Hind III, Pst I, Pvu II, and Taq I); 46 with the DQ $\beta$ probe and 24 with the DQ $\alpha$ probe. Since $83 \%$ of the HLADQ1/DQ2 heterozygotes were Ro/SSA precipitin positive, combinations of RFLPs that represented combinations of HLA-DQ1 and HLA-DQ2 alleles were considered in the initial analysis. The RFLPs were divided into four groups based upon their association with HLA-DQ1 or HLA-DQ2 $(P<0.005$ by two-tailed Fisher's exact test) and whether they were detected by the $\mathrm{DQ} \alpha$ or $\mathrm{DQ} \beta$ gene probe (Table I). The $\mathrm{DQ} 1 \alpha$ group is composed of four RFLPs detected by the DQ $\alpha$ probe and associated with HLA-DQ1: Hind III $7.6 \mathrm{~kb}$, Pst I $16.0 \mathrm{~kb}$, Pvu II $4.8 \mathrm{~kb}$, and Eco RI $16.0 \mathrm{~kb}$. The DQ2 $\alpha$ group has only the Pvu II $2.8 \mathrm{~kb}$ RFLP. The DQ1 $\beta$ group contains five RFLPs: Pst I $13.0 \mathrm{~kb}$, Bam HI $3.0 \mathrm{~kb}$, Pvu II $2.2 \mathrm{~kb}$, Eco RI $2.2 \mathrm{~kb}$, and Eco RV $4.9 \mathrm{~kb}$. Finally, the DQ2 $\beta$ group also contains five RFLPs: Bam HI 4.2 kb, Hind III 13.0 kb, Pst I 5.5 kb, Pvu II $1.7 \mathrm{~kb}$, and Pvu II $2.4 \mathrm{~kb}$.

The RFLP of each group most closely associated with the presence of a Ro/SSA precipitin was selected as a representative for subsequent analysis. Since the DQ $1 \alpha$ and DQ2 $\beta$ RFLPs together were the most closely related to the HLADQ1/DQ2 heterozygotes (Table I), this pair was predicted to be more closely associated with the presence of Ro/SSA precipitins than any other combination of HLA-DQ1 and DQ2 RFLPs. The RFLP data from 67 SLE patients were used to test this hypothesis by stepwise logistic regression (32). The four possible pairwise combinations related to HLA-DQ1 and DQ2 of the four RFLP groups (DQ1 $\alpha$ and DQ2 $\alpha$, DQ $1 \alpha$ and DQ2 $\beta$, $\mathrm{DQ} 1 \beta$ and $\mathrm{DQ} 2 \alpha$, and $\mathrm{DQ} 1 \beta$ and $\mathrm{DQ} 2 \beta$ ) were evaluated for their possible contribution to anti-Ro/SSA (Table II). Only the DQ $1 \alpha$ and DQ2 $\beta$ RFLP combination represented by the Pvu II $4.8 \mathrm{~kb}(\mathrm{DQ} \alpha)$ and Pvu II $1.7 \mathrm{~kb}(\mathrm{DQ} \beta)$ was incorporated into

Table I. RFLPs Detected by $D Q \alpha$ or DQR Gene Probes Associated with HLA-DQ1 or HLA-DQ2

$\begin{array}{cccccc}\text { Restriction } & \text { DNA } & \text { HLA-DQ1 } & \text { HLA-DQ2 } & \text { HLA-DQ1/DQ2 } \\ \text { Probe } & \text { enzyme } & \text { fragment } & \text { (P) } & \text { Anti-Ro/SSA } & \text { (P) }\end{array}$

$k b$

DQ1 $\alpha$ RFLP (HLA-DQ1 associated RFLP with DQ $\alpha$ probe)

$\begin{array}{llllll}\mathrm{DQ} \alpha & \text { Pvu II } & 4.8 & <10^{-7} & 0.04^{*} & 0.22\end{array}$

DQ1 $\beta$ RFLP (HLA-DQ1 associated RFLP with DQ $\beta$ probe)

$\begin{array}{llll}\mathrm{DQ} \beta & \text { Bam HI } & 3.0\end{array}$

$0.18^{*}$

DQ2 $\alpha$ RFLP (HLA-DQ2 associated RFLP with DQ $\alpha$ probe)

DQ $\alpha \quad$ Pvu II $\quad 2.8$

DQ2 $\beta$ RFLP (HLA-DQ2 associated RFLP with DQ $\beta$ probe)

$\mathrm{DQ} \beta$

Pvu II

1.7

$0.38^{*}$

$<10^{-5}$

0.007

0.01

Associations of RFLPs with the serologically defined alleles HLA-DQ1, HLA-DQ2 and HLA-DQ1/DQ2 heterozygotes as well as with anti-Ro/ SSA from 55 SLE patients are presented as $P$ values from a two-tailed Fisher's exact test. Only RFLPs associated with HLA-DQ1 or HLA-DQ2 at $P<0.005$ are considered. One representative of each RFLP group is presented. * Negative associations (odds ratio $<1.0$ ). 
Table II. A RFLP Combination at HLA-DQ Associated with Ro/ SSA Precipitins and Predicting a Gene Complementation Effect

\begin{tabular}{ccccccc}
\hline & & & \multicolumn{3}{c}{ Improvement } \\
\cline { 5 - 6 } Step & Term in model & $\mathrm{df}^{*}$ & $\chi^{2}$ & $P$ & Coefficient $^{*}$ \\
\hline 1 & DQ $1 \alpha$ and DQ2 $\beta$ & 1 & 13.3 & $<0.005$ & $3.1 \pm 1.1$
\end{tabular}

Stepwise logistic regression model of anti-Ro/SSA in HLA-typed SLE patients was predicted by combinations of the RFLP groups defined by association with HLA-DQ1 or HLA-DQ2 alleles and by hybridization to the $\mathrm{DQ} \alpha$ or $\mathrm{DQ} \beta$ cDNA probes. These included the representative RFLPs presented in Table $I$ in the following combinations: $\mathrm{DQ} 1 \alpha$ and $\mathrm{DQ} 2 \alpha, \mathrm{DQ} 1 \alpha$ and $\mathrm{DQ} 2 \beta, \mathrm{DQ} 1 \beta$ and $\mathrm{DQ} 2 \alpha$, and $\mathrm{DQ} 1 \beta$ and $\mathrm{DQ} 2 \beta$. Complete data for this analysis were available in 67 patients. Pvu II $4.8 \mathrm{~kb}$ and Pvu II $1.7 \mathrm{~kb}$, representing the DQ1 $\alpha$ and DQ2 $\beta$ RFLP groups was the only DQ1- and DQ2-associated RFLP combination incorporated into the model. The associated RFLPs within each group were then substituted for the representative RFLPs and tested in all combinations by logistic regression along with this RFLP pair. In each case the Pvu II 4.8-kb and 1.7-kb pair was the RFLP pair most closely related to the presence of Ro/ SSA precipitins.

* Degrees of freedom.

$\ddagger$ Coefficient \pm standard error.

the model (Table II). The remaining capacity of the other three RFLP combinations to change the model was quite small ( $P$ $\geqq 0.2$ ). The gene interaction effect at HLA-DQ observed in serologic typing data, therefore, was explained by the DQ1 $\alpha$ and DQ2 $\beta$ RFLP combination.

Gene complementation requires complementing effects derived from each of two different genetic loci. These data fulfill this requirement. To satisfy the hypothesis that the antiRo/SSA response is at least partially restricted by the presence of a particular $\alpha \beta$ heterodimer molecule of HLA-DQ would require that one parental chromosome code for the $\mathrm{DQ} \alpha$ peptide while the other code for $\mathrm{DQ} \beta$. That these data define such an outcome and that both $\mathrm{DQ} \alpha$ and $\mathrm{DQ} \beta$ peptides are commonly polymorphic (33) is consistent with the formation of a particular $\alpha \beta$ DQ heterodimer as a molecular explanation for the observed gene complementation associated with anti-Ro/ SSA production in these SLE patients. In recent data obtained by transfecting homozygous cell lines with different $D Q \beta$ alleles, the $\mathrm{DQ} 1 \alpha / \mathrm{DQ} 2 \beta$ heterodimer molecule was not found (34). The significance of these observations for the interpretation of the detailed molecular mechanism of gene complementation for the generation of anti-Ro/SSA in these patients must await the direct evaluation for the presence of the hypothesized molecule in SLE patients.

While the HLA-DQ1/DQ2 heterozygotes show a strong association with anti-Ro/SSA neither HLA-DQ1 nor HLADQ2 alone are associated with anti-Ro/SSA (Table III). Of the RFLPs representative of HLA-DQ1 and HLA-DQ2, only the DQ2 $\beta$ RFLP is associated with anti-Ro/SSA. (The data presented in Table III for the Eco RV 20-kb RFLP detected by the $\mathrm{DQ} \beta$ probe is discussed below.) While there may be some racial difference in the relationships of particular RFLPs to anti-Ro/SSA, individuals with both the DQ $1 \alpha$ and DQ2 $\beta$ RFLPs are associated with anti-Ro/SSA in both blacks and whites. Moreover, in the entire SLE cohort those with DQ1 $\alpha$ and DQ2 $\beta$ define the group most closely associated with antiRo/SSA. Nearly half (49\%) of the anti-Ro/SSA precipitin posi-

Table III. Associations of Anti-Ro/SSA with HLA-DQ1 and DQ2 Serologic Alleles and RFLPs in SLE*

\begin{tabular}{|c|c|c|c|c|c|c|c|c|c|}
\hline & \multicolumn{3}{|c|}{ Serologic alleles } & \multicolumn{6}{|c|}{ RFLPs } \\
\hline & DQ1 & DQ2 & $\mathrm{DQ1/DQ2}$ & $\mathrm{DQ1} \alpha$ & $\mathrm{DQ} 1 \beta$ & $\mathrm{DQ} 2 \alpha$ & $\mathrm{DQ} 2 \beta$ & $\mathrm{DQ} 1 \alpha / \mathrm{DQ} 2 \beta$ & EcoRV20 \\
\hline All SLE patients & \multicolumn{3}{|c|}{$n=62$} & \multicolumn{6}{|c|}{$n=67$} \\
\hline Allele present & 42 & 31 & 18 & 48 & 29 & 53 & 32 & 20 & 11 \\
\hline āRo with allele & 28 & 21 & 15 & 27 & 17 & 29 & 23 & 17 & 10 \\
\hline āRo without allele & 8 & 15 & 21 & 8 & 18 & 6 & 12 & 18 & 25 \\
\hline$F$ statistic & 2.07 & 2.40 & 7.21 & 1.08 & 0.82 & 0.61 & 10.7 & 14.6 & 8.67 \\
\hline$P$ value & 0.16 & 0.13 & 0.010 & 0.30 & 0.37 & 0.44 & 0.0017 & 0.0003 & 0.0045 \\
\hline Black patients & \multicolumn{3}{|c|}{$n=22$} & \multicolumn{6}{|c|}{$n=23$} \\
\hline Allele present & 15 & 11 & 8 & 17 & 8 & 17 & 10 & 7 & 8 \\
\hline $\bar{a}$ Ro with allele & 12 & 10 & 8 & 12 & 6 & 14 & 10 & 7 & 8 \\
\hline āRo without allele & 4 & 6 & 8 & 4 & 10 & 2 & 6 & 9 & 8 \\
\hline$F$ statistic & 0.62 & 4.0 & 5.45 & 0.03 & 0.16 & 5.88 & 10.6 & 4.97 & 6.39 \\
\hline$P$ value & 0.44 & 0.059 & 0.030 & 0.86 & 0.70 & 0.024 & 0.0037 & 0.037 & 0.020 \\
\hline White patients & \multicolumn{3}{|c|}{$n=38$} & \multicolumn{6}{|c|}{$n=42$} \\
\hline Allele present & 26 & 20 & 10 & 30 & 21 & 34 & 21 & 12 & 3 \\
\hline āRo with allele & 15 & 11 & 7 & 14 & 11 & 14 & 13 & 9 & 2 \\
\hline āRo without allele & 4 & 8 & 12 & 4 & 7 & 4 & 5 & 9 & 16 \\
\hline$F$ statistic & 1.95 & 0.40 & 2.18 & 0.60 & 1.54 & 0.20 & 3.64 & 8.12 & 0.73 \\
\hline$P$ value & 0.17 & 0.53 & 0.15 & 0.44 & 0.22 & 0.66 & 0.064 & 0.0069 & 0.40 \\
\hline
\end{tabular}

* Alleles are defined by serologic reactivity or as RFLPs which are largely defined in Table I. Eco RV20 is the 20-kb fragment detected by the $\mathrm{DQ} \beta$ probe after digestion with the Eco RV restriction endonuclease. Only patients with complete serologic data $(n=62)$ or with RFLP data complete for the alleles presented $(n=67)$ are considered. The number of patients in each category is presented. One American Indian and a Chinese patient are included in the total group. The $F$ statistic presented compares the likelihood of anti-Ro/SSA being found with as opposed to without the allele and for all SLE patients is used in the initial simple statistics of the logistic regression analyses presented in Tables II and IV. $P$ values from the $F$ statistic are not corrected for multiple comparisons. Anti-Ro/SSA is abbreviated to āRo. 
tive patients have the DQ1 $\alpha$ and DQ2 $\beta$ RFLP combination (from Table III, odds ratio $=9.1,95 \%$ confidence interval 4.6 to 18.3 , sensitivity $=0.49$, specificity $=0.91$, and predictive value $\mathbf{0} 0.85$ )

Other effects between RFLPs and anti-Ro/SSA may also be present and they may be as important as or more important than the DQ $1 \alpha$ and DQ2 $\beta$ RFLP combination in other cohorts of SLE patients. To detect such additional effects in this sample of SLE patients, model building with stepwise logistic regression has been continued by including all RFLPs associated with Ro/SSA precipitins as potential independent variables along with the DQ1 $\alpha$ and DQ2 $\beta$ RFLP combination. Associations of individual RFLPs with anti-Ro/SSA have been found only with the $D Q \beta$ gene probe. They include an Eco RV $20.0 \mathrm{~kb}$ fragment $(P=0.002)$ as well as two RFLPs of the DQ2 $\beta$ RFLP group, Pvu II $1.7 \mathrm{~kb}$ and Bam HI $4.2 \mathrm{~kb}(P$ $<0.005)$. These RFLPs, along with three other RFLPs less closely associated with Ro/SSA precipitins, have been evaluated individually and together along with the DQ $1 \alpha$ and DQ2 $\beta$ RFLP combination in stepwise logistic regression models of anti-Ro/SSA. The DQ $1 \alpha$ and DQ2 $\beta$ RFLP combination has always made the greatest contribution to each model and is consistently incorporated first (Table IV). Subsequently, only the Eco RV $20.0 \mathrm{~kb}$ RFLP detected with the DQ $\beta$ probe is incorporated into the model. The Eco RV $20.0 \mathrm{~kb}$ RFLP is associated with HLA-DR7 in these SLE patients $(P<0.003)$ nearly all of whom are HLA-DQ2 positive as has been found in normal donors by others (35-37). This RFLP did not hybridize to a DR $\beta$ gene probe (38) and therefore does not reflect variation at HLA-DR. Unlike the HLA-DQ1/DQ2 effect (Table II) no RFLP detected with $\mathrm{DQ} \alpha$ was preferentially associated with the DQ $\beta$ Eco RV 20-kb fragment in Ro/SSA precipitin positive SLE patients (analysis is not presented). The DQ $1 \alpha$ and DQ2 $\beta$ RFLP combination or the DQ $\beta$ Eco RV 20.0-kb RFLP is associated with 21 of the $35(60 \%)$ Ro/SSA precipitin positive SLE patients, while only 3 of the $32(9 \%)$ Ro/SSA precipitin negative patients had either (odds ratio $14.5,95 \%$ confidence interval 3.3 to 55 ).

The distribution of HLA alleles in human populations as well as the linkage disequilibrium found between alleles at different HLA loci are known to vary between ethnic groups. For example, the HLA-B8 and HLA-DR3 are found together in North American whites more frequently than expected and

Table IV. Final Logistic Regression Model of the Contribution of HLA-DQ RFLPs to anti-Ro/SSA in SLE

\begin{tabular}{llccccc} 
& & & \multicolumn{2}{c}{ Improvement } \\
\cline { 5 - 6 } Step & Term in final model & $\mathrm{df}^{*}$ & $x^{2}$ & $P$ & Coefficient \\
\hline 1 & $\mathrm{DQ} 1 \alpha$ and $\mathrm{DQ} 2 \beta$ & 1 & 13.3 & $<0.0005$ & $2.0 \pm 0.70$ \\
2 & Eco RV 20.0 kb (DQ $\beta)$ & 1 & 4.7 & 0.030 & $2.1 \pm 1.1$
\end{tabular}

Stepwise logistic regression analysis of the RFLPs contributing to anti-Ro/SSA has been performed in 67 SLE patients. DQ1 $\alpha$ and DQ2 $\beta$ indicate the respective RFLPs, Pvu II $4.8 \mathrm{~kb}$ and Pvu II 1.7 $\mathrm{kb}$, identified in Table II. DQ $\beta$ RFLPs independently associated with anti-Ro/SSA in these SLE patients $(P<0.05)$ have also been tested for inclusion in this model including Bam HI $4.2 \mathrm{~kb}$, Taq I $7.0 \mathrm{~kb}$, Hind III 15.0 kb, Pst I 5.5 kb, Pvu II 1.7 kb, Eco RV 20.0 kb.

* Degrees of freedom.

${ }^{\ddagger}$ Coefficient \pm standard error. with other associated alleles constitute a haplotype not ordinarily found in other ethnic groups (35). As noted above a third of the SLE patients in this cohort are black and twothirds are white (Table III). The frequencies of the HLA-DQ1 and DQ2 serologic alleles as well as the DQ1 or DQ2 associated RFLPs (Table I) are very similar in both the white and black SLE patients of this study. The Eco RV 20-kb RFLP, however, is an example of a genetic marker more commonly found in the black patients in this study than in the whites $(P$ $<0.02$ ). A larger relative contribution to the association of Ro/SSA precipitins with either the Eco RV $20.0 \mathrm{~kb}$ RFLP or the HLA-DR7 serologically defined allele is derived from the black SLE patients. Both racial groups appear to contribute to the association of Eco RV $20.0 \mathrm{~kb}$ with Ro/SSA precipitins as presented in the final model (Table IV). A previous study has found Ro/SSA precipitins to be primarily related to HLADR7 in black patients with SLE (39). The Eco RV 20-kb RFLP reported here may be a molecular marker for this serologic allele in such patients. In the white patients the DQ1 $\alpha$ / DQ2 $\beta$ RFLP combination was closely related to anti-Ro/SSA precipitins while the Eco RV $20.0 \mathrm{~kb}$ DQ $\beta$ fragment made virtually no additional contribution.

The data and analysis of these SLE patients suggest additional observations concerning previous work. First, linkage disequilibrium between HLA-DR3 and HLA-DQ2 as well as HLA-DR2 and HLA-DQ1 means that at least a component of the association of HLA-DR3 and HLA-DR2 with anti-Ro/ SSA $(2,3,40-45)$ may be reflected by the gene products related to $\mathrm{DQ} 1 \alpha$ and $\mathrm{DQ} 2 \beta$ in combination. Second, the multiplicity and complexity of the histocompatibility relationships may cause these or other histocompatibility mechanisms to predominate in particular cohorts of patients. In this cohort, both the Eco RV 20-kb RFLP and the DQ1 $\alpha$ and DQ2 $\beta$ RFLP combination require an allele associated with HLA-DQ2. This is consistent with the DQ $\beta$ RFLPs of HLA-DQ2 being strongly associated with anti-Ro/SSA. Third, the presence of two histocompatibility antigens related to an autoantibody in SLE is consistent with the proposed model for clinical heterogeneity of SLE where once the individual expresses the now unknown fundamental immune defect of SLE, the particular autoantibodies produced are determined at least in part by histocompatibility composition (7). Fourth, since the anti-Ro/SSA precipitin results were identical in this group of SLE patients with bovine and human Ro/SSA antigen sources, the recently appreciated species variation in the Ro/SSA antigen does not influence these results (46). The complexity of the Ro/SSA immune response as reflected by the multiple Ro/SSA peptides suggests that additional levels of immune discrimination will be found with the analysis of more restricted antigenic specificities of the Ro/SSA antigenic particle.

There is good evidence for the DQ1 $\alpha$ and DQ2 $\beta$ RFLPs reflecting allelic variants at HLA-DQ. First, each is strongly associated in this SLE patient group with an HLA-DQ serologically defined allele. Second, there is no evidence of cross-hybridization to HLA-DR with any DQ2 $\beta$ group RFLP since a $\mathrm{DR} \beta$ probe (38) failed to hybridize to any of DQ2 $\beta$ RFLPs. Third, both RFLPs from the DQ1 $\alpha$ and DQ2 $\beta$ groups are most closely associated with DQ alleles in other studies (36, 37, 47).

Further, the data support another allele at the DR $\beta$ or the $\mathrm{DQ} \beta$ locus which is associated with the HLA-DQ2, DR7 haplotype being related to Ro/SSA precipitins. These results support the existence of multiple class II molecular mechanisms 
for the anti-Ro/SSA autoimmune response in SLE. One is likely to involve an $\alpha \beta$ heterodimer gene complementation product of the HLA-DQ locus, while in a second a class II $\beta$ peptide gene product at HLA-DR7 or HLA-DQ2 is important. Moreover, these histocompatibility alleles must serve as restriction elements for the autoimmune response in SLE. Hence, some of the variation in autoimmune response between SLE patients may be attributed to differences in histocompatibility composition, thereby demonstrating an important analogy to the immune response against ordinary, nonautoimmune antigens. The conclusion follows that the autoimmune response in the example of anti-Ro/SSA in SLE is dependent upon an antigen and is not the result of autonomous B lymphocyte activation. These data define some of the normal molecular machinery of the immune response used in generating an autoimmune antibody response.

\section{Acknowledgments}

We are grateful to Ms. Kathy Hardgrave for technical assistance, to Dr. Bo Dupont for sharing an unpublished manuscript and to Dr. J. Donald Capra for providing CDNA probes.

This work has been supported by U. S. Public Health Service grants (AI-24717, AR-39577, AR-31133, AI-21568, AR-32214), the March of Dimes Birth Defects Foundation (1-1109), the Lupus Foundation of America, the Oklahoma Lupus Association, Inc., and the Oklahoma Health Research Program. Dr. Frank is an Alumni Research Scholar of the University of Oklahoma College of Medicine.

\section{References}

1. Dorf, M. E., and B. Benacerraf. 1975. Complementation of $\mathbf{H}-2$ linked Ir genes in the mouse. Proc. Natl. Acad. Sci. USA. 72:36713675.

2. Dorf, M. E. 1978. Complementation of $\mathbf{H}-2$ genes controlling immune responsiveness. Springer Semin. Immunopathol. 1:171-206.

3. Charron, D. J., V. Lotteau, and P. Turmel. 1984. Hybrid HLADC antigens provide molecular evidence for gene trans-complementation. Nature (Lond.). 312:157-195.

4. Giles, R. C., R. Demars, C. C. Chang, and J. D. Capra. 1985. Allelic polymorphism and trans-complementation of molecules encoded by the HLA-DQ subregion. Proc. Natl. Acad. Sci. USA. 82:1776-1780.

5. Rosenshine, S., I. Cascino, A. Zeevi, R. J. Duquesnoy, and M. Trucco. 1986. DQ $\alpha$ and $\beta$ RFLP reveals the composition of the DQ molecule recognized by $T$ cell clones. Immunogenetics. 23:187-196.

6. Harley, J. B., M. Reichlin, F. C. Arnett, E. L. Alexander, W. B. Bias, and T. T. Provost. 1986. Gene interaction at HLA-DQ enhances autoantibody production in primary Sjögren's syndrome. Science (Wash. DC). 232:1145-1147.

7. Harley, J. B., A. S. Sestak, L. G. Willis, S. M. Fu, J. A. Hansen, and M. Reichlin, M. 1989. A model for the clinical heterogeneity of systemic lupus erythematosus. Arthritis Rheum. 32:826-836.

8. Hamilton, R. G., J. B. Harley, W. B. Bias, M. Roebber, M. Reichlin, M. C. Hochberg, and F. C. Arnett. 1988. Two Ro(SS-A) autoantibody responses in systemic lupus erythematosus: correlation of HLA-DR/DQ specificities with quantitative expression of Ro(SS-A) autoantibody. Arthritis Rheum. 31:496-505.

9. Wolin, S., and J. A. Steitz. 1983. Genes for two small cytoplasmic Ro RNAs are adjacent and appear to be single-copy in the human genome. Cell. 32:735-744.

10. Deutscher, S. L., J. B. Harley, and J. D. Keene. 1988. Molecular analysis of the $60 \mathrm{kD}$ human Ro ribonucleoprotein. Proc. Natl. Acad. Sci. USA. 85:9479-9483.

11. Ben-Chetrit, E., B. J. Gandy, E. M. Tan and K. F. Sullivan. 1989. Isolation and characterization of a cDNA clone encoding the
60-kD component of the human SS-A/Ro ribonucleoprotein autoantigen. J. Clin. Invest. 83:1284-1292.

12. Yamagata, H., J. B. Harley and M. Reichlin. 1984. Molecular properties of the Ro/SSA antigen and enzyme-linked immunosorbent assay for quantitation of antibody. J. Clin. Invest. 74:725-733.

13. Ben-Chetrit, E., K. L. Chan, F. Sullivan and E. M. Tan. 1988. A $52 \mathrm{kD}$ protein is a novel component of the SS-A/Ro antigenic particle. J. Exp. Med. 167:1560-1567.

14. Rader, M. D., C. A. O'Brien, Y. Lin, J. B. Harley and M. Reichlin. 1989. The heterogeneity of the Ro/SSA antigen: Different molecular forms in the lymphocyte and red blood cells. J. Clin. Invest. 83:1293-1298.

15. Maddison, P. J., and M. Reichlin. 1979. Deposition of antibodies to a soluble cytoplasmic antigen in the kidneys of patients with systemic lupus erythematosus. Arthritis Rheum. 22:858-863.

16. Maddison, P. J., H. Magavero, and M. Reichlin. 1978. Patterns of clinical disease associated with antibodies to nuclear ribonucleoprotein. J. Rheumatol. 5:407-411.

17. Penner, E., and M. Reichlin. 1982. Primary biliary cirrhosis associated with Sjögren's syndrome: evidence for circulating and tissue-deposited Ro/anti-Ro immune complexes. Arthritis Rheum. 25:1250-1253.

18. Molina, R., T. T. Provost, and E. L. Alexander. 1985. Two types of inflammatory vascular disease in Sjögren's syndrome: differential association with seroreactivity to rheumatoid factor and antibodies to Ro(SS-A) and with hypocomplementemia. Arthritis Rheum. 28:1251-1258.

19. Scott, J. S., P. J. Maddison, P. V. Taylor, E. Essher, D. Scott, and R. P. Skinner. 1983. Connective tissue disease, antibodies to ribonucleoprotein, and congenital complete heart block. N. Engl. J. Med. 309:209-212.

20. Harley, J. B., J. L. Kaine, O. F. Fox, M. Reichlin, and B. Gruber. 1985. Ro(SS-A) antibody and antigen in a patient with congenital complete heart block. Arthritis Rheum. 28:1321-1325.

21. Mond, C. B., M. G. E. Peterson, and N. F. Rothfield. 1989. Correlation of anti-Ro antibody with photosensitivity rash in systemic lupus erythematosus. Arthritis Rheum. 32:202-204.

22. Lee, L. A., K. K. Gaither, S. Coulter, D. A. Morris, and J. B. Harley. 1989. The pattern of cutaneous IgG deposition in a case of subacute cutaneous lupus erythematosus is reproduced by infusing purified anti-Ro(SSA) autoantibodies into human skin-grafted mice. $J$. Clin. Invest. 83:1293-1298.

23. Tan, E. M., A. S. Cohen, J. F. Fries, A. T. Masi, D. J. McShane, N. F. Rothfield, J. G. Schaller, N. Talal, and R. J. Winchester. 1982. The 1982 revised criteria for the classification of systemic lupus erythematosus. Arthritis Rheum. 25:1271-1277.

24. Clark, G., M. Reichlin, and T. B. Tomasi. 1969. Characterization of a soluble cytoplasmic antigen reactive with the sera from patients with systemic lupus erythematosus. J. Immunol. 102:117-120.

25. Wasicek, C. A., and M. Reichlin. 1982. Clinical and serological differences between systemic lupus erythematosus patients with antibodies to Ro versus patients with antibodies to Ro and La. J. Clin. Invest. 69:835-843, 1982.

26. Terasaki, P. I. 1965. Microdroplet assay for human blood lymphotoxins. In Histocompatibility Testing. National Academy of Sciences, Washington, DC. 171.

27. Southern, E. M. 1975. Detection of specific sequences among DNA fragments separated by gel electrophoresis. J. Mol. Biol. 98:503-517.

28. Feinberg, A. D., and B. Vogelstein. 1983. A technique for radiolabeling DNA restriction endonuclease fragments to high specific activity. Anal. Biochem. 32:6-13.

29. Feinberg, A. P., and B. Volgelstein. 1984. Addendum to a technique for radiolabeling DNA restriction endonuclease fragments to high specific activity. Anal. Biochem. 137:266-267.

30. Auffray, C., A. J. Korman, M. Roux-Dosseto, R. Bono, and J. L. Strominger. 1982. DNA clone for the heavy chain of human B cell 
alloantigen DC1. Strong sequence homology to the HLA-DR heavy chain. Proc. Natl. Acad. Sci. USA. 79:6337-6341.

31. Larhammer, D., L. Schenning, K. Gustafsson, K. Wiman, L. Claesson, L. Rask, and P. A. Peterson. 1982. Complete amino acid sequence of an HLA-DR antigen-like $\beta$ chain as predicted from the nucleotide sequence: similarities with immunoglobulins and HLA-A, -B, and -C antigens. Proc. Natl. Acad. Sci. USA. 79:3687-3691.

32. Engleman, L. 1985. Stepwise logistic regression. In BMDP Software Manual. W. J. Dixon, editor. University of California Press, Berkeley, CA. 330-334.

33. Figueroa, F., and J. Klein. 1986. The evolution of MHC Class II genes. Immunol. Today. 7:78-90.

34. Kwok, W. W., D. Schwarz, B. S. Nepom, R. A. Hock, P. S. Thurtle, and G. T. Nepom. 1989. HLA-DQ molecules from $\alpha-\beta$ heterodimers of mixed allotype. J. Immunol. 141:3123-3127.

35. Tiwari, J. L., and P. I. Terisaki. 1985. HLA and Disease Associations. Springer-Verlag, New York. 4-17.

36. Cohen, D., I. LeGall, A. Marcadet, M.-P. Font, J.-M. Lalouel, and J. Dausset. 1984. Clusters of HLA Class II $\beta$ restriction fragments describe allelic series. Proc. Natl. Acad. Sci. USA. 81:7870-7874.

37. Simons, M. J., R. Wheeler, J.-M. Lalouel, and B. Dupont. 1989. Restriction fragment length polymorphism of HLA genes: summary of the 10th International Workshop Southern blot analysis. In Immunobiology of HLA. Volume I. Histocompatibility 1987. B. Dupont, editor. Springer-Verlag, New York. 959-1023.

38. Long, E. O., C. T. Wake, J. Gorski, and B. Mach. 1983. Complete sequence of an HLA-DR $\beta$ chain deduced from a cDNA clone and identification of multiple non-allelic DR $\beta$ chain genes. $E M B O$ (Eur. Mol. Biol. Organ.) J. 2:389-394.

39. Wilson, W. A., E. Scopelitis, and J. P. Michalski. 1984. Association of HLA-DR7 with both antibody to SSA(Ro) and disease susceptibility in blacks with systemic lupus erythematosus. J. Rheumatol. 11:653-657.
40. Maddison, P. J., and D. A. Bell. 1980. Serologic subsets in systemic lupus erythematosus: an examination of autoantibodies in relationship to clinical features of disease and HLA antigens. Arthritis Rheum. 23:714-715.

41. Ahearn, J. M., T. T. Provost, C. A. Dorsch, M. B. Stevens, W. B. Bias, and F. C. Arnett. 1982. Interrelationships of HLA-DR, MB, and MT phenotypes, autoantibody expression and clinical features in systemic lupus erythematosus. Arthritis Rheum. 25:10311040.

42. Alvarellas, A., J. M. Ahearn, T. T. Provost, C. A. Dorsch, M. B. Stevens, W. B. Bias, and F. C. Arnett. 1983. Relationships of HLA-DR and MT antigens to autoantibody expression in systemic lupus erythematosus. Arthritis Rheum. 26:1533-1535.

43. Wilson, R. W., T. T. Provost, W. B. Bias, E. L. Alexander, D. W. Edlow, M. C. Hochberg, M. B. Stevens, and F. C. Arnett. 1984. Sjögren's syndrome: influence of multiple HLA-D region alloantigens on clinical and serologic expression. Arthritis Rheum. 27:1245-1253.

44. Hochberg, M. C., R. E. Boyd, J. M. Ahearn, F. C. Arnett, W. B. Bias, T. T. Provost, and M. B. Stevens. 1985. Systemic lupus erythematosus: a review of clinico-laboratory features and immunogenic markers in 150 patients with emphasis on demographic subsets. Medicine 64:285-295.

45. Harley, J. B., E. L. Alexander, W. B. Bias, O. B. Fox, T. T. Provost, M. Reichlin, H. Yamagata, and F. C. Arnett. 1986. Anti-Ro/ SSA and anti-La/SSB in patients with Sjögren's syndrome. Arthritis Rheum. 29:196-206.

46. Reichlin, M., M. Rader, and J. B. Harley. 1989. Autoimmune response to the Ro/SSA particle is directed to the human antigen. Clin. Exp. Immunol. 76:373-377.

47. LeGall, I., A. Marcadet, M.-P. Font, C. Auffray, J. Strominger, J.-M. Lalouel, J. Dausset, and D. Cohen. 1986. Exuberant restriction fragment length polymorphism associated with the DQ $\alpha$-chain gene and the DX $\alpha$-chain gene. Proc. Natl. Acad. Sci. USA. 82:5433-5436. 